Volume 14 - Número 2 - ago/dez de 2019

\title{
UM OLHAR PARA OS PROCESSOS REFERENCIAIS EM CONVERSAS NO WHATSAPP
}

\author{
A LOOK INTO THE REFERENTIAL PROCESSES IN WHATSAPP \\ CONVERSATIONS
}

\author{
Aparecida Juliana da Silva ${ }^{1}$ \\ Thaís Ludmila da Silva Ranieri ${ }^{2}$
}

\begin{abstract}
RESUMO: Neste trabalho, nos propomos a analisar os processos referenciais construídos em conversas de um grupo de WhatsApp, observando, com atenção, a performance das elaborações referenciais, conforme defendem Mondada e Dubois (2003) e Koch (2004), em contextos multissemióticos. Juntamente com essas discussões, relacionamos esses pressupostos às novas concepções de texto, embasados nos estudos de Cavalcante e Custódio Filho (2010) e nas contribuições de Hodge e Kress (1988), Dionísio (2005) e Jewitt (2014) a respeito dos aspectos multimodais da linguagem. Para isso, analisamos prints de conversas de um grupo de família no aplicativo WhatsApp. As interações do grupo foram acompanhadas por um período de aproximadamente 10 dias no mês de março de 2018. Nossos resultados apontam para uma integração entre os modos semióticos, como o verbal e as imagens, no intuito de estabelecer a progressão referencial em conversas no aplicativo WhatsApp. Tal integração corrobora não só com a natureza multissemiótica do texto, mas também nos mostra como os processos textuais se articulam para além do verbal, apontando para a potencialidade da integração das demais semioses como um fator importante para a textualidade.
\end{abstract}

PALAVRAS-CHAVE: Processos referenciais. Multimodalidade. WhatsApp.

ABSTRACT: This work aims to analyze the referential processes made in a chat of a group on WhatsApp, noticing, carefully, the performance of the referential elaborations in multisemiotic contexts, according to Mondada and Dubois (2003) and Koch (2004). Taking into consideration these discussions, we relate these assumptions with new concepts of text, based on Cavalcante and Custódio Filho (2010) studies and Hodge and Kress (1988), Dionísio (2005) e Jewitt (2014) contributions to the language multimodal aspects. For that, we analysed screenshots of a family group chat on WhatsApp. The group interactions were followed for a period of approximately 10 days in March 2018. Our results point out to a connection between semiotic modes, as well as verbal and images, intending to set up a referential progression in chats on WhatsApp. This connection confirms not only the multisemiotic nature of text, but also presents how the textual processes are articulated beyond the verbal, indicating the semiosis connections competences as a relevant factor for the textuality.

KEY-WORDS: Referential processes. Multimodality. WhatsApp.

\section{Apresentação}

Nos últimos anos, boa parte dos usuários de telefones móveis tem em seus aparelhos o aplicativo WhatsApp instalado. Desde a metade desta década, o WhatsApp vem se consolidando como uma das ferramentas com a maior quantidade de usuários ativos e vem se consolidando como um dos principais meios de comunicação no Brasil (FERREIRA; ARRUDA FILHO, 2014). À medida que o número de usuários aumenta, aumenta também a

\footnotetext{
${ }^{1}$ Graduada em Letras pela Universidade Federal Rural de Pernambuco/Unidade Acadêmica de Serra Talhada. E-mail: julianahsilva@outlook.com.br

${ }^{2}$ Doutora em Letras pela Universidade Federal de Pernambuco e Professora Adjunta 3 do

Departamento de Educação da Universidade Federal Rural de Pernambuco. E-mail:

thaisranieri@yahoo.com.br
} 
Volume 14 - Número 2 - ago/dez de 2019

forma como as interações mediadas pelo aplicativo passam a ser reguladas por novas possibilidades de uso da língua em associação com semioses de outras naturezas. O verbal vem articulado a emojis, emoticons, cores, sons, imagens. O fluxo da interação é marcado por características da língua falada e da língua escrita. Logo, o texto não pode ser encarado como uma entidade puramente verbal e os elementos de textualidade e as construções referenciais passam a sofrer modificações que clamam por um olhar mais atento para a articulação entre o verbo e os outros modos semióticos. Ou seja, há uma ressignificação de uso da língua que precisa ser pensada, tendo em vista o uso de aplicativos de mensagens que chegaram hoje como mediadores de nossas interações.

Diante desse cenário, o presente trabalho busca refletir sobre os processos referenciais dentro desse contexto multissemiótico. Para isso, iniciamos a discussão com o papel do objeto texto em novos ambientes, buscando reforçar o seu aspecto multimodal, tendo por base as contribuições de Cavalcante e Custódio Filho (2010). Logo após, trazemos as discussões em torno da Multimodalidade, tomando por base as discussões de Hodge e Kress (1988), Dionísio (2005) e Jewitt (2014). Em seguida, enveredamos para uma discussão sobre os processos referenciais em uma abordagem multimodal. Nessa seção, retomamos estudos clássicos da referenciação, como Mondada e Dubois (2003) e Koch (2004), mas apontando para as novas possibilidades que vislumbram a associação entre os processos verbais em articulação com as demais semioses que são acionadas e permitidas pelo aplicativo WhatsApp. Tal ponto se mostra mais detalhado nas análises em que mostramos, através de prints de conversas, como se dá a construção referencial sob essas novas condições. Entretanto, antes de adentrarmos na seção dedicada às análises, apresentamos um aspecto geral do aplicativo WhatsApp e mostramos como se deu o processo metodológico de coleta de dados. Por último, fechamos com as considerações finais que refletem sobre os resultados obtidos e aponta reflexões para o estudo em questão.

\section{O texto para além do verbal}

A defesa atual, originalmente defendida por Beaugrande, ao definir texto como "um evento comunicativo em que convergem ações linguísticas, culturais, sociais e cognitivas" (1997, p. 10 apud CAVALCANTE, 2013, p. 18), parte da noção de que os efeitos de um texto, tanto sobre quem o escreve quanto sobre quem o lê, transcendem os muros de sua estruturação física, cuja força é capaz de transformar seus interlocutores em agentes sociais numa relação sociointeracional. Entendemos que a construção de um texto se configura em um movimento de "vai-e-vem", em que a fala ou a escrita dependerá tanto da situação comunicativa, quanto do contexto compartilhado entre os falantes.

Segundo Cavalcante e Custódio Filho (2010, p. 62), “o caráter do texto, no estágio atual dos estudos em LT (Linguística de Texto), fala em favor de um objeto dinâmico, multifacetado, resultante de uma atividade linguístico-sociocognitiva, na qual se incluem parâmetros discursivos". Quer dizer, fala em favor do social, porque a interação entre os falantes é constante; e do cognitivo, porque se demanda uma espécie de negociação mental em relação aos conhecimentos implícitos a serem compartilhados entre os interlocutores no ato discursivo.

Os autores admitem, nesse caso, texto e discurso como sendo indissociáveis. Isso porque o texto não é apenas a materialização dos discursos, nem o discurso é a "imitação" dos textos: e sim, que os textos atuam como "(re)formuladores" de novos discursos, à medida que alcançam seus interlocutores, assim como são estabelecidos no interior dos próprios discursos. Ou seja, estamos diante de uma relação de interdependência entre os dois, cuja definição se assemelha muito ao que Ciulla Silva (2008) afirma, ao dizer que "o texto não é simplesmente 
Volume 14 - Número 2 - ago/dez de 2019

uma superfície material que conduz ao discurso, mas é visto como indissociável dele e é definido pelo uso" (p. 26 apud CAVALCANTE; CUSTÓDIO FILHO, 2010, p. 59).

Para Cavalcante e Custódio Filho (2010), definir o que vem a ser um texto é complexo, uma vez que envolve a multiplicidade das operacionalizações em sua produção. Mesmo assim, afirmam que o contexto linguístico (o cotexto), por si só, não garante nem parte do sentido textual, tendo em vista que, para isso, é preciso ser acionados inúmeros outros recursos, dos quais o processamento mental e a cultura são indispensáveis, não de maneira independente, mas constitutivamente interligados. Os pesquisadores explicam que o texto mobiliza um conjunto de saberes indeterminados, cujas articulações serão manifestadas em dadas situações sociodiscursivas, num determinado contexto sociocultural, para formação de sentido.

O texto é uma unidade de sentido, principalmente se considerarmos que qualquer sujeito, a menos que seja acometido por um déficit cognitivo, sempre constituirá textos semanticamente coerentes, pois "não há produção linguística que se pretenda sem 'sentido"” (CAVALCANTE; CUSTÓDIO FILHO, 2010, p. 63). Aqui, definitivamente, alargamos expressivamente os limites do texto, transcendemos as paredes do campo verbal e passamos a incluir todas as outras formas de comunicação que, em sua constituição, carreguem sentido, como os outros recursos de caráter semiótico: tais como os imagéticos e as cores, por exemplo.

Temos, então, uma quebra da primazia do verbo, por meio da inclusão de diversas semioses ao que denominamos por texto. Por isso mesmo, Cavalcante e Custódio Filho (2010, p. 66) dizem que "não se trata, portanto, de fazer uma linguística sem língua, mas de levar às últimas consequências a tese de que a comunicação se efetiva a partir da conjunção entre diversos fatores, sendo a multissemiose um dos mais relevantes".

Dessa forma, não é mais possível limitarmos os efeitos de sentido de um texto a elementos puramente linguísticos, principalmente porque, cada dia mais, a produção de textos e dos recursos multimodais têm-se se propagado em uma velocidade demasiadamente rápida. Por isso, podemos hoje facilmente afirmar que boa parte da população, que possui acesso à internet e às redes sociais, passa a maior parte de seu tempo, produzindo textos e formulando discursos que articulam as diversas semioses dentro desse universo.

\section{Situando a Multimodalidade}

Toda comunicação é e sempre foi multimodal (KRESS; VAN LEEUWEN, 1996). Seja face a face ou a distância, síncrona ou assíncrona, cada instância de comunicação depende de mais de um modo para fazer sentido. Hoje, isso pode parecer um lugar-comum; mas, historicamente, o papel atribuído ao verbal, e, especialmente. ao modo de escrever, ofusca a multiplicidade de recursos moldados socialmente para se comunicar. Assim, concebemos aqui língua(gem) como uma atividade multimodal cuja agregação do verbal aos elementos não verbais é algo rotineiro em nossas práticas sociais. Em todas as nossas ações discursivas, sejam elas orais ou escritas, há uma mescla de semioses que são acionadas como recursos indissociáveis do verbal. Bem mais do que uma opção estilística da linguagem, a multimodalidade é um elemento constitutivo de nossas práticas sociais.

A multimodalidade encontra suas origens na adaptação da estrutura das funções da linguagem de Halliday a outros modos além da fala e escrever que podemos encontrar no trabalho seminal de Kress e van Leeuwen, a saber, Reading Images: The Grammar of Visual, lançado em 1996. A abordagem aqui adotada comunga com as discussões propostas pela Semiótica Social que marca uma nova abordagem para os estudos semióticos. Para Hodge e Kress (1988), trata-se de uma nova fase para os estudos semióticos ao entender a semiose humana como um fenômeno social que está em suas origens, em suas funções, seus contextos e em seus efeitos. A Semiótica Social abarca "os significados sociais construídos através das 
Volume 14 - Número 2 - ago/dez de 2019

diversas formas semióticas, por meio de textos semióticos e práticas semióticas em todos os tipos da sociedade humana em todos os períodos da história humana" (HODGE; KRESS, 1988, p. 261, tradução nossa).

O conceito foi introduzido e desenvolvido nas últimas duas décadas para explicar os diferentes recursos utilizados na comunicação para expressar significado. O termo é usado para descrever um fenômeno da comunicação humana e para identificar um campo diversificado e crescente de pesquisa. Como fenômeno da comunicação, a multimodalidade define a combinação de diferentes recursos semióticos, ou modos, em textos e eventos comunicativos, como imagem estática e em movimento, fala, escrita, layout, gesto e proxêmica. Já como campo de investigação, a pesquisa em multimodalidade preocupa-se com desenvolvimento de teorias, ferramentas analíticas e descrições que abordam o estudo da representação e comunicação considerando os modos como um princípio organizador. Por fim, como fenômeno da comunicação, o termo é usado não apenas por analistas multimodais, mas também, e cada vez mais, por trabalhos em disciplinas preocupadas com textos e significados, como linguística e estudos de comunicação, os quais, no entanto, tendem a dedicar seu foco analítico à linguagem.

O campo dos "estudos multimodais" adota quatro suposições principais (JEWITT 2014), a saber: (a) toda comunicação é multimodal; (b) análises focadas exclusiva ou principalmente na linguagem não podem responder adequadamente significado; (c) cada modalidade possui recursos específicos decorrentes de sua materialidade e de sua condição social histórias que moldam seus recursos para atender às necessidades comunicativas; e (d) os modos concordam juntos, cada um com um papel especializado, na criação de significado; portanto, as relações entre os modos são fundamentais para entender todas as instâncias de comunicação.

A multimodalidade como campo de pesquisa concebe a representação e a comunicação como um recurso multiplicidade de modos, todos desenvolvidos socialmente como recursos para dar sentido. Modos como gesto, som, imagem, cor ou layout, por exemplo, são concebidos como conjuntos de recursos que as sociedades desenvolveram - cada um com um nível maior ou menor de articulação em diferentes grupos sociais - criar significado e expressar e moldar valores, ideologias e relações de poder. Quando combinados com a fala ou a escrita, eles não são um mero acompanhamento ou apoio a linguagem verbal, mas são elementos importantes na construção dos sentidos.

Dionísio (2005), corrobora com as propostas dos principais autores da Semiótica Social e nos apresenta claramente a força da atuação multimodal na construção dos discursos, em suas diferentes modalidades. A autora explica que, na interação oral, seja em sua forma mais primitiva (face a face), seja mediada por recursos tecnológicos (bate-papo virtual), a multimodalidade desempenha atuação inerente no discorrer comunicativo, configurando-se a partir da imbricação mútua entre, no mínimo, a relação fala e gesto. Semelhantemente acontece no texto escrito, que demanda não somente do texto em si (palavras), mas também do seu suporte: uma folha impressa (tipografia) ou uma tela de computador (animações), por exemplo.

Ou seja, a multimodalidade no ato comunicativo sempre existiu, contudo, com o passar do tempo, a interação entre os sujeitos tem demandado, mais do que nunca, da inserção de novas e diferentes semioses para produção de seus textos. A multimodalidade se expande junto às mudanças ideológicas e culturais de um povo, que a introdução de novos recursos, ao que entendemos por texto, não apenas o torna mais atrativo, mas também o torna mais inclusivo. Dessa forma, tais elementos, tanto se mostram de forma indispensável na construção de sentido dos textos, quanto surgem a partir de necessidades transculturais de um povo em interação. 
Volume 14 - Número 2 - ago/dez de 2019

\section{$4 O$ processo de referenciação e as suas estratégias textuais}

Apoiando-se nas contribuições de Mondada e Dubois (2003) e de Koch (2004), passaremos a discutir o conceito de referenciação. Em conformidade com as autoras, entendemos a referenciação como uma progressão "viva", não estancada, que se estabelece no movimento da atividade interativa entre os sujeitos sociocognitivos, numa relação indireta e, por vezes, cientificamente arbitrária sobre o mundo; contudo, de total acordo com o contexto no qual estão situados. Nesse sentido, normalmente não é o material aparente que define as categorias, mas o negociado cognitivamente que nem sempre é verbalizado, mas que se mostra em concordância com o contexto do mundo. Para exemplificação, Mondada e Dubois (2003) citam o piano como um instrumento musical no contexto de um concerto ou como um móvel pesado e incômodo no contexto de uma mudança. Tal objeto se mostra suscetível a tantas outras categorizações dependendo do lugar situacional que se constrói o discurso.

Dessa forma, entendemos que as categorias não são dadas, e sim, são "o resultado de reificações práticas e históricas de processos complexos, compreendendo discursões, controvérsias, desacordos" (MONDADA; DUBOIS, 2003, p. 28). São, na verdade, totalmente influenciadas pelo meio socio-histórico de circulação, afetando diretamente o fluxo constitutivo dos objetos de discurso emersos na atividade interativa. Ou seja, é justamente devido a esse caráter instável das categorias, as quais se modelam de acordo com as transformações sociais, que podemos, durante as trocas discursivas, construir um objeto de discurso por meio de diversas possibilidades categóricas.

Os referentes são moldados durante a atividade discursiva, podendo ser operacionalizados por meio das escolhas significativas dos sujeitos sobre o material linguístico à sua disposição. De acordo com Koch e Elias (2006), "as formas de referenciação são escolhas do sujeito em interação com outros sujeitos, em função de um querer-dizer" (p. 124). Nesse sentido, apenas reforçamos nossa defesa em relação ao que admitimos como objetos de discurso, os quais se (re)constroem dentro do próprio processo de interação, através de uma sofisticação cognitiva que não se confunde com a realidade do mundo.

É possível evidenciarmos esse trabalho cognitivo, de maneira mais palpável, quando analisamos melhor os processos de ativação/reativação na memória decorrentes das formas de remissão dos interlocutores no ato comunicativo. Como sabemos, a construção/ativação do objeto de discurso (categorização) pode, em qualquer momento, sofrer operacionalizações que o levem a uma reconstrução/reativação desse mesmo objeto (recategorização), a partir de estratégias cognitivas capazes de encapsularem/sumarizarem ou rotularem à medida que o discurso se desenvolve.

$\mathrm{O}$ encapsulamento atua com função de sumarizar as informações expressas anteriormente, encapsulando-as em uma expressão nominal. Semelhantemente, os rótulos são expressões nominais de parte do cotexto que o precede, capaz de estabelecer um novo referente que, por sua vez, poderá constituir o tema dos enunciados subsequentes. Vejamos o exemplo abaixo:

Sem conseguir acabar com a greve dos caminhoneiros, o governo Michel Temer pressiona a Polícia Federal a acelerar investigações e prender suspeitos de dar suporte ilegal ao movimento. A ofensiva atípica em cima da PF ignora o fato de os inquéritos serem sigilosos e estarem em fase inicial e se dá em meio a diversas tentativas frustradas de interromper a paralisação ${ }^{3}$. (grifo nosso).

No exemplo, a expressão nominal "a ofensiva atípica" além de encapsular, sumarizar as informações precedentes, rotula o segmento, de modo que dá abertura para o

\footnotetext{
${ }^{3}$ Fonte: Portal FolhaPE, 29 maio 2018.
} 
Volume 14 - Número 2 - ago/dez de 2019

prosseguimento extensivo do texto. Nesse caso, estamos diante daquilo que chamamos por formas híbridas, referenciadoras e preditivas, pois atuam em função cognitivo-discursiva dupla, referenciando toda uma sequência de informações, ao passo que, também, posiciona-se como elemento de previsão para as futuras ideias que se seguirão.

Esse fenômeno, como pode ser percebido, introduz mudanças ou desvios do tópico, entretanto, preservando a continuidade da informação principal, isto é, são alocadas informações novas dentro do quadro informacional dado, formando a ligação entre tópicos e subtópicos. Assim, o texto ganha o que denominamos como organização macroestrutural, que, a partir de suas construções textuais complexas, responsabiliza-se pelo movimento simultâneo de retroação e progressão.

No mais, podemos perceber como os objetos de discurso passam a ser construídos e reconstruídos ao longo da atividade interativa, que, conforme esclarece Koch (2004), "[os objetos de discurso] são, portanto, altamente dinâmicos, ou seja, uma vez introduzidos na memória discursiva, vão sendo constantemente transformados, recategorizados no curso da progressão verbal" (p.79).

Além dessas questões expostas anteriormente, podemos ainda salientar a multimodalidade no processo de construção da referência. Ramos (2012) vem mostrando que a referenciação não é uma atividade apenas pautada no verbal. $\mathrm{O}$ autor mostra que em tiras que não apresentam nenhum elemento verbal existem estratégias de progressão textual que ocorrem também em textos verbais, como: a introdução de referente, a retomada e a recategorização. $\mathrm{O}$ leitor desse tipo de texto aciona elementos cognitivos, culturais, linguísticos para garantir a construção de sentidos e, por conseguinte, a progressão textual. Segundo o autor, outros modos de comunicação são acionados como elementos necessários para a elaboração dos referentes no jogo enunciativo. Não são adereços que enfeitam os recursos verbais, mas, são constitutivos do processo de elaboração dos referentes em qualquer tipo de interação.

Ainda dentro do escopo da condição multimodal da referência, Morato (2001) afirma que a construção da referência prevê uma arbitragem de fatores que pressupõem o linguístico, mas, ao mesmo tempo, transcendem-no. Em sua colocação, podemos perceber a necessidade de se ter o plano linguístico, mas também de associá-lo a outros elementos, bem como a outras organizações semióticas, ressaltando, assim, uma concatenação entre elementos verbais e nãoverbais na construção da referência.

\section{O lócus da pesquisa: WhatsApp}

O WhatsApp é uma rede social que funciona por meio de aplicativo de mensagens gratuito e criado em 2009. A rede permite trocar mensagens pelo telefone celular ou computador, além de possibilitar o compartilhamento de inúmeros recursos textuais, compreendendo desde a escrita e a fala, à recursos de natureza audiovisual, sonora e imagética. Sua influência na vida dos seus usuários tem ganhado grandes proporções, à medida que sua utilização se amplia e se moderniza, exigindo apenas o acesso a um computador ou celular inteligente, junto à conexão com a Internet, para desfrutar de suas ferramentas.

Através das pesquisas realizadas por Ferreira e Arruda Filho (2014), evidenciou-se que o WhatsApp tem sido um dos aplicativos de rede social mais bem aceitos pelos usuários, ao que concerne a sua facilidade de uso, sua confiabilidade e gama de serviços. Vejamos o que os autores falam sobre isso:

os usuários consideram o WhatsApp como universal, rico, mais leve, confiável, e não pensam em trocá-lo por outro, demonstrando claramente a admiração pela rede. Eles não se importam com outras redes competidoras e nem com problemas técnicos, ou pagamentos, essa rede para eles expressa o 
Volume 14 - Número 2 - ago/dez de 2019

que há de melhor em termos de tecnologia de redes sociais (FERREIRA; ARRUDA FILHO, 2014, p. 10).

Ou seja, essa junção de características que definem o aplicativo, o garante maior utilização por também se adaptar às necessidades práticas cotidianas dos sujeitos, em relação aos seus processos interacionais comunicativos. Sua acelerada troca de informações, juntamente com suas funcionalidades mais leves para o aparelho móvel, o torna ainda mais satisfatório à realidade da sociedade moderna.

Além disso, mais que atualizar informações e permitir a comunicação em tempo real, também se configura como um aplicativo de maior privacidade, tendo em vista que, somente aqueles que possuem o número pessoal ou profissional, poderão interagir com o(os) possível(is) interlocutor(es).

O WhatsApp é considerado como uma rede mais reservada e de socialização mais íntima, pois para compartilhar de sua rede o usuário deve ter o número de celular, que é mais particular, e no Facebook o usuário com um click adiciona amigos, conhecidos e conhecidos de conhecidos, fazendo com que a rede fique imensurável, e todos tem acesso a quase todas as informações disponíveis nos perfis (FERREIRA; ARRUDA FILHO, 2014, p.12).

Na citação acima, os autores fazem uma breve comparação distinta entre os modus operandi do WhatsApp e do Facebook. O caráter reservado do WhatsApp, como apresentado, permite, pelo menos a priori, pensar que os indivíduos que dele faz acesso, faz para conversar com pessoas mais íntimas: família, amigos, colegas de trabalho, etc., as quais propicia uma interação mais espontânea e casual à luz de suas relações de contato. Ou seja, essas relações aproximam ainda mais a interação virtual ao que seria uma relação pessoal, em virtude de todos os recursos fornecidos: criar grupos, enviar mensagens ilimitadas com imagens, vídeos e áudio, comunicar-se gravando e enviando mensagens com som ou vídeo.

\section{Metodologia e critérios para escolha do corpora}

Esta pesquisa se caracteriza como uma pesquisa qualitativa, considerando que nosso foco não recai sobre a quantidade de ocorrências do fenômeno observado, uma vez que lidam com "interpretações das realidades sociais" (BAUER, GASKEL; p. 23, 2002) e, por essa razão, se opõem as pesquisas positivistas/quantitativas que lidam com mensurações.

Adotamos também as contribuições de Mavers e Kress (2015) para o que chamam de metodologia multimodal. Segundo eles, “(...) um enfoque semiótico social de textos multimodais procura compreender os significados construídos com cada modo, como se distribuem esses significados e as relações que existem entre eles" (p. 229). Para os autores, ao assumirmos tal perspectiva no tratamento dos dados, somos levados a selecionar o que será observado e, por sua vez, o que será transcrito para a composição do corpus. Ou seja, nem tudo será reapresentado. "Em virtude da complexidade da interação, que faz a transcrição, pode optar por incluir certos modos e excluir outros" (MAVERS; KRESS, 2015, p. 228).

Diante dessas considerações, o corpus utilizado em nossas pesquisas foi coletado de um grupo familiar de WhatsApp. Sob o nome Família..., o grupo foi criado no dia 28 de março de 2016, por um dos membros que ainda permanece atuante no grupo, estando atualmente composto por 21 participantes. Nosso interesse pelo grupo Família... se deu pelo fato de ser um ambiente no qual a interação comunicativa entre seus integrantes acontecia diariamente se comparado a outros grupos observados naquele período. Salientamos que os sujeitos que integram o grupo estão cientes dos objetivos da pesquisa. Eles também foram 
devidamente esclarecidos quanto aos tipos de divulgação que a pesquisa poderia ter, além de serem informados que as suas identidades e registros telefônicos seriam protegidos.

Outro fator a ser considerado foi a natureza e a dinamicidade das mensagens que circulavam por ele, as quais eram praticadas de maneira inteiramente informal, como também através de multimodos diversos. Para este trabalho, selecionamos quatro imagens de conversas, coletadas em formato de print, cujas datas de ocorrência se deram no período de 09 a 19 de março de 2018.

Para efeito de esclarecimento, ressaltamos ainda que algumas das imagens printadas tiveram repercussões maiores em relação a outras. Veremos que alguns objetos de discurso receberam maior foco, se quando comparado a outros que foram somente categorizados pelo mesmo integrante a postá-lo. Perceberemos que a imprevisibilidade discursiva, em um grupo composto por vários participantes, é muito comum e acentuada devido, entre outras coisas, que a sua repercussão depende da relevância sociocognitiva, até certo ponto, estabelecida pelo grupo.

Assim, nesta pesquisa, optamos por se forcar nos elementos verbais, nas imagens e nos áudios ${ }^{4}$. Foram descartados os emojis, emoticons ou outro elemento gráfico que não estivesse vinculado às categorias de análise selecionadas: os processos de encapsulamento e de rotulação que representam o modo verbal escrito associado aos modos imagético e sonoro, representado pela função áudio do Whatsapp.

\section{Análise do corpus}

Após a discussão teórica e a descrição dos aspectos metodológicos adotados, passamos a esta seção que se propõe a análise dos dados. Assim, para darmos início as análises, começamos com as duas imagens abaixo. Vejamos:

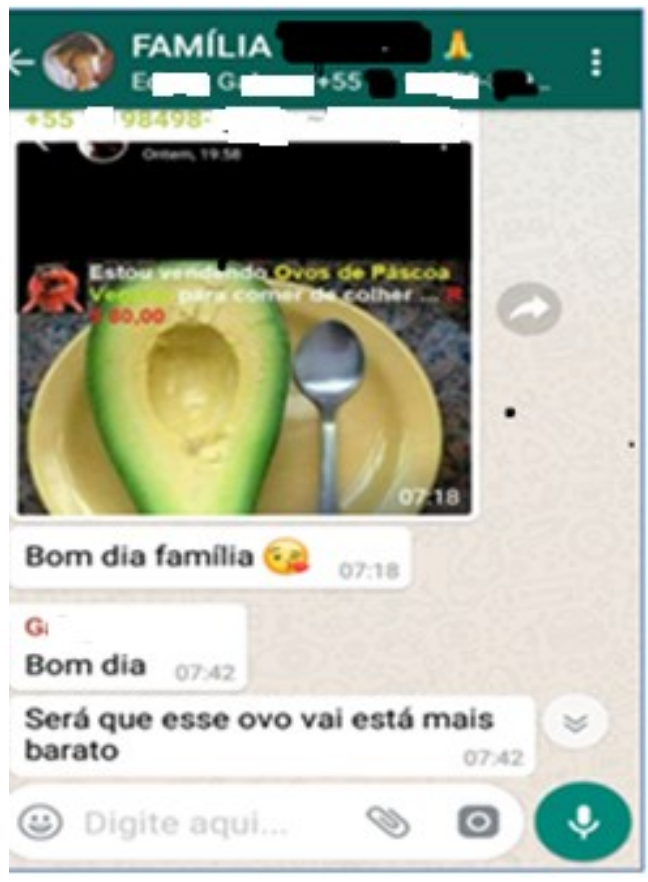

Imagem 1

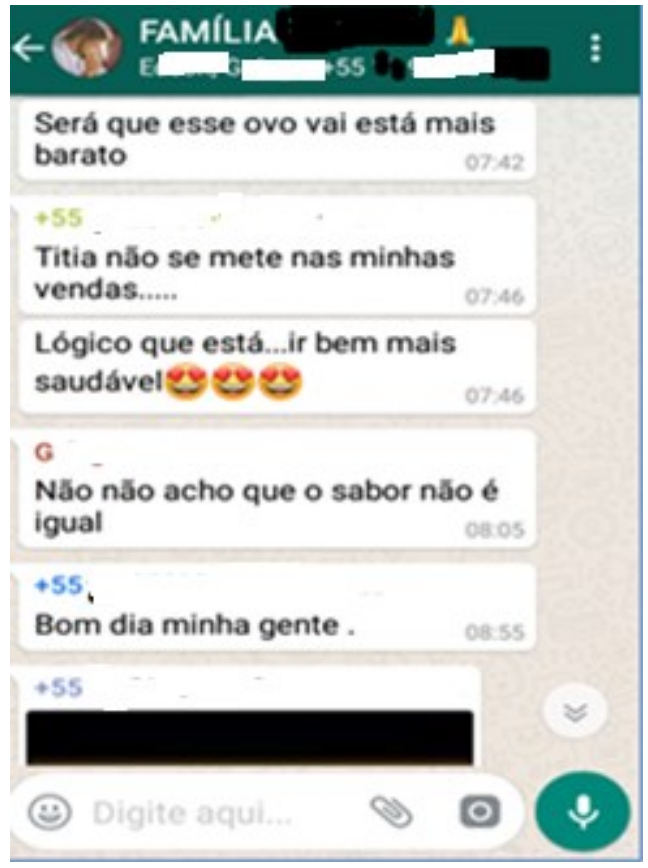

Imagem 2

\footnotetext{
${ }^{4}$ A transcrição dos áudios seguiu as indicações do Projeto Nurc. PRETI D. (org) O discurso oral culto $2^{\text {a }}$. ed. São Paulo: Humanitas Publicações - FFLCH/USP, 1999 - (Projetos Paralelos. V.2) 224p.
} 
Volume 14 - Número 2 - ago/dez de 2019

$\mathrm{Na}$ imagem 1, encontramos a postagem de um meme, que, no intuito de fazer rir, traz uma proposta alimentícia mais saudável para o feriado do dia de Páscoa. A comicidade desse texto, que mescla diversas semioses em sua configuração, se fundamenta na comparação feita entre o Ovo de Páscoa de Chocolate e o abacate (fruta com formato semelhante ao do alimento comparado), pois, atrelada ao contexto de circulação ${ }^{5}$, implicitamente, faz uma crítica aos preços abusivos ofertados pelos estabelecimentos que vendem esse produto na época da Páscoa. Nota-se essa crítica quando observamos o preço divulgado no post, $\mathrm{R} \$ 80,00$ por um abacate, cujo preço da fruta, no Brasil, tem variado de $\mathrm{R} \$ 0,91$ a $\mathrm{R} \$ 5,00^{6}$, dependendo da região de onde se é vendida. O efeito cômico se eleva sob a proposta de ser um ovo mais saudável, sugerido pelo termo "Vegano" que aparece escrito em cor verde.

Cavalcante e Custódio Filho (2010), ao tratarem sobre os efeitos de sentido de um texto, estendido para além da exclusividade verbal, afirmam que: "o estudo dos sentidos a partir do uso interativo da linguagem tem de ultrapassar os limites materiais da superfície textual. $\mathrm{O}$ cotexto, embora fundamental como ponto de partida, não garante a completude dos sentidos" (CAVALCANTE; CUSTÓDIO FILHO, 2010, p. 60). A assertiva, defendida pelos autores, faz analogia direta com o nosso exemplo, tendo em vista que, para interpretá-lo, necessário se fez exceder o material linguístico (cotexto), e considerar as inúmeras operacionalizações sociocognitivas envolvidas no ato interpretativo do meme, bem como as outras semioses integradas ao texto, que, nesse exemplo, vincula-se à imagem.

Nesse caso, ainda que inconscientemente, o integrante do grupo que faz essa postagem, está levando em consideração o contexto social no qual se insere sua comunidade de fala, no objetivo de que os outros participantes acionem as informações necessárias para que a compressão se efetive de maneira integral. Quer dizer, a sofisticação dos processamentos cognitivos, no interior de uma interação, é diversa; pois, entre outras coisas, implica inferir informações que, a priori, precisam estar condizentes com os conhecimentos compartilhados, culturalmente, entre seus falantes.

Ainda em relação ao meme da Imagem 1, com base nos pressupostos defendidos por Dionísio (2007), sobre a multimodalidade nas interações comunicativas, o verbal e as demais semioses se apresentam mutuamente imbricados no cerne da construção de sentido. Tanto a comicidade quanto a crítica acima mencionada, constroem-se de modo simultâneo junto às leituras da sentença - "Estou vendendo Ovos de Páscoa Vegano para comer de colher... R\$ $\underline{80,00 "}$ ", e da imagem - abacate sem caroço ao lado de uma colher. Tal fato apenas justifica o pensamento da autora, em relação ao todo interpretativo a ser considerado na leitura de textos multimodais, quando afirma:

Assim, referimo-nos à multimodalidade discursiva como um traço constitutivo a todos os gêneros textuais escritos e orais. Consequentemente, recursos visuais e verbais precisam ser vistos como um todo, no processamento dos gêneros textuais (DIONÍSIO, 2007, p. 178).

Retomando nossas discussões sobre referenciação, observamos, no decorrer da atividade interacional, que outro membro do grupo categoriza nosso objeto de discurso a partir da expressão "esse ovo". Embora esteja claro, para todos, que o meme não apresenta, de fato, um Ovo de Páscoa, naquele contexto de fala, os integrantes modelam o seu sentido real no mundo, para que obedeça ao advento "de práticas simbólicas mais do que de uma ontologia dada" (MONDADA; DUBOIS, 2003, p. 20). Isto é, a negociação, entre os falantes, opera escolhas significativas com foco à concretização de sua proposta de sentido, sendo essa

\footnotetext{
${ }^{5}$ É válido lembrar que a coleta do corpus de análise ocorreu entre os dias 09 a 19 de março de 2018, datas, relativamente, próximas ao Feriado do dia de Páscoa, que, nesse ano vigente, aconteceu no dia 1 de abril.

${ }^{6}$ Fonte: Agrolink, 21 jul. 2018.
} 
categoria dependente do contexto. Assim, "A discursivização ou textualização do mundo por intermédio da linguagem não se dá como um simples processo de elaboração de informação, mas de (re)construção interativa do próprio real" (KOCH, 2004, p. 59).

Então, a expressão "esse ovo", além de categorizar todo o fenômeno antecedente, dá margem as próximas discussões evidenciadas na Imagem 2. Tais discussões, como podemos ver, se apresentam embebidas pela negociação intersubjetiva dos falantes, manifestadas através das próximas sentenças proferidas: "[...] bem mais saudável" e "[...] o sabor não é igual". Em nenhum momento, essas sentenças desrespeitam o acordo estabelecido: que é o de não confundir a realidade com o universo simbólico negociado na interação.

Nos exemplos seguintes, evidenciamos outras formas de construção referencial, engendradas durante as trocas conversacionais de nosso grupo. Vejamos como isso acontece:

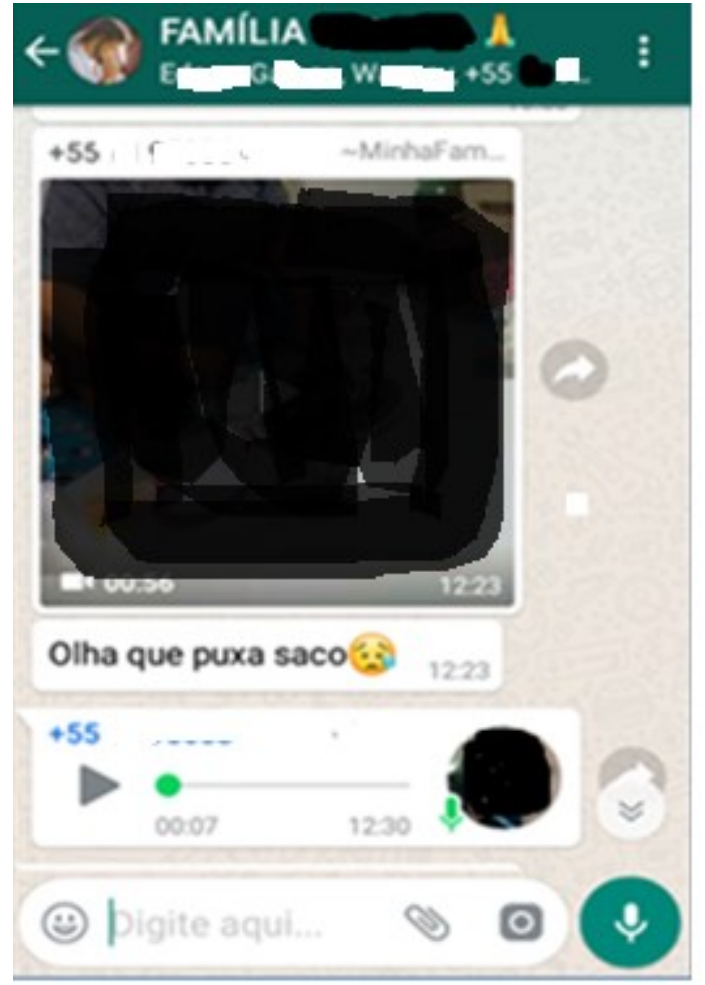

Imagem 3

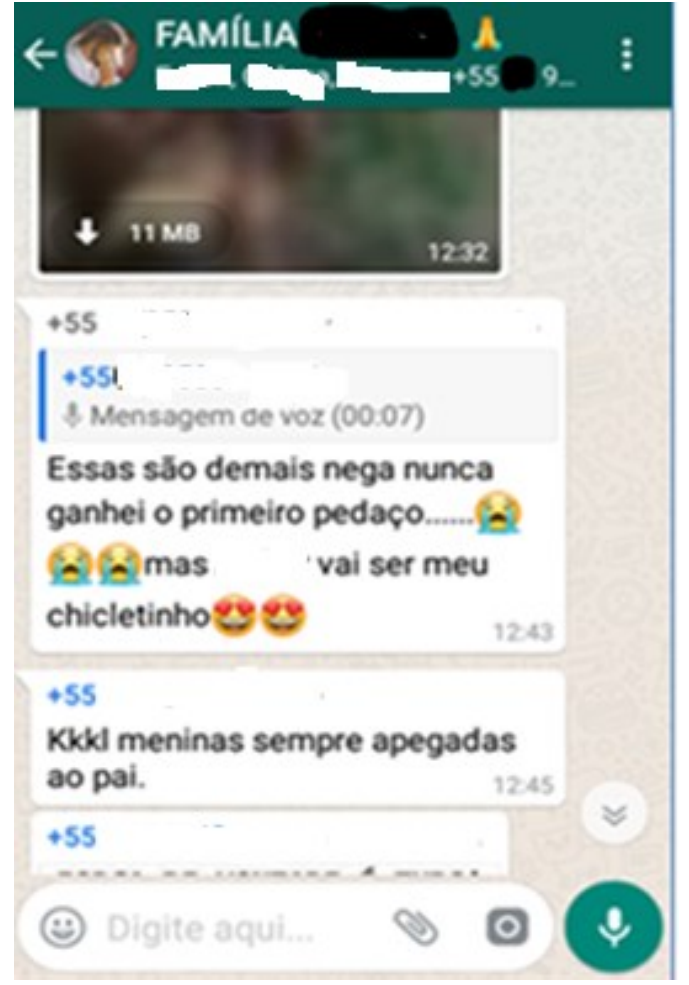

Imagem 4

Na Imagem 3, evidenciamos a postagem de um vídeo, no qual a mesma integrante que o postou categoriza sua ação a partir da expressão "puxa saco". O enredo do vídeo mostra o momento em que a filha da integrante do grupo, dá o primeiro pedaço de bolo, de seu aniversário, para o pai. Nesse caso, um pouco diferente do que vimos nos exemplos anteriores, a expressão "puxa saco", que significa o ato de bajular ou adular ${ }^{7}$, referencia sim uma ação, mas não a ação por inteira, e sim, a ação específica da criança, ou seja, categoriza a criança.

Essa expressão referencial faz remissão à ação da criança, encapsulando-a na expressão "puxa saco". Contudo, além de sumarizar a ação, também atua como rótulo retrospectivo, pois, se continuarmos analisando a sequência discursiva, observamos que, esse termo, permite o estabelecimento de um novo referente: o apego de meninas pelo pai, apresentado na Imagem 4, sob a sentença "kkkl meninas sempre apegadas ao pai". "Percebemos que as nominalizações são (...) resultantes de encapsulamento operados sobre predicações antecedentes ou subsequentes, ou seja, sobre processos e seus actantes, os quais passam a ser

\footnotetext{
${ }^{7}$ Fonte: Dicionário Houaiss.
} 
Volume 14 - Número 2 - ago/dez de 2019

representados como objetos-acontecimento na memória discursiva dos interlocutores" $(\mathrm{KOCH}$, 2004, p. 66).

Como explica Koch (2004), mais uma vez identificamos o papel cognitivo do uso da linguagem, isso porque é preciso que o grupo reconheça e compartilhe do sentido dessa expressão, para que, dessa forma, possa associar o termo à ação já estabelecida em suas memórias discursivas, a qual foi vivenciada no vídeo. É preciso que o grupo compartilhe da comicidade sugerida, aceitando a categorização da criança como bajuladora do pai, ao invés de carinhosa com o pai, por exemplo. Tendo feito isso, os interlocutores, em negociação, apropriam-se da inteireza semântica do discurso, bem como estarão aptos para ativar ou desativar tais referentes quando quiserem, durante o processo de interação.

É importante citar que, nesse exemplo, temos aquilo que chamamos por formas híbridas, referenciadoras e preditivas $(\mathrm{KOCH}$; ELIAS, 2006), que, além de recuperar informações antecedentes difusas (encapsulamento), também veicula informações novas (rotulação).

Abaixo do vídeo, temos uma mensagem de voz, na qual a interlocutora diz: "Tadinha... só teve o direito de cortar o bolo, num foi? ((risos))". Nessa mensagem, evidenciamos a predicação “tadinha”, referindo-se a mãe da criança. Através dessa expressão, explicitada no texto oral, percebemos uma nova remissão, em relação ao vídeo, contudo, agora, voltada para a referenciação do referente "mãe" e não mais do referente "filha". Podemos atribuir à expressão "tadinha", como sendo um dos principais elementos que corroboram com a desfocalização ou mudança do tópico discursivo em vigência - "puxa saco" -, passando a atuar como uma espécie de par adjacente.

Assim como vemos no desenvolvimento interacional, exposto na Imagem 4, a expressão "tadinha" atua como principal elemento que favorece a transição do tópico/referente textual até então tratado como principal. Isto é, nesse momento, deixamos de focalizar nossas atenções no referente filha, para focarmos no referente mãe, o que passa a ser justificado, posteriormente, pela sentença "nunca ganhei o primeiro pedaço".

Mais claro se mostra tal fenômeno, quando observamos o recurso utilizado pela integrante do grupo, que é o de retomar, especificamente, a mensagem de voz no seu ato de resposta; o que a permite não somente explicar sua condição, como também expandir sua manifestação de descontentamento, por meio do uso do pronome demonstrativo "essas". A expressão "essas", nesse sentido, embora faça alusão as suas filhas, torna-se o próprio elemento de transição, viabilizando as próximas construções referencias, dissolvidas da primeira categorização: "puxa saco".

Em geral, o que percebemos, com esse exemplo, é que o processo referencial vai sendo gradativamente construído na busca de se alcançar a melhor adequação relacional sobre a situação. Isso se dá, principalmente, porque o ambiente de produção do WhatsApp permite essas reformulações devido estar também intimamente ligado ao discurso de natureza oral. Para tanto, Mondada e Dubois (2003, p. 30) explicam: "A referenciação adequada pode ser vista como um processo de construção de um caminho ligando diferentes denominações aproximadas que não são excluídas pela última". Ou seja, as denominações, ou categorizações, vão sendo inseridas ao longo da comunicação no objetivo de atingir um objeto de discurso mais apropriado, finalmente expressado pela sentença "meninas sempre apegadas ao pai".

\section{Considerações Finais}

Nossos resultados indicam uma articulação entre os modos semióticos, como o objetivo de estabelecer a progressão referencial em conversas no aplicativo WhatsApp. As análises que foram realizadas mostram o potencial efeito das estratégias de referenciação, em 
Volume 14 - Número 2 - ago/dez de 2019

conversas informais de WhatsApp, quando atreladas aos recursos multimodais disponíveis pelo aplicativo: nesta pesquisa, o uso de imagens e vídeos, áudios e a sua ferramenta de retomada a mensagens específicas. Observamos que tais recursos oportunizam uma dinâmica referencial mais diversificada, devido ao uso interativo desses variados recursos.

As análises mostram também o potencial efeito das estratégias de referenciação, em conversas informais de WhatsApp, quando atreladas aos recursos multimodais disponíveis pelo aplicativo. Observamos que tais recursos oportunizam uma dinâmica referencial mais diversificada, dada ao uso interativo desses variados recursos. O que nos leva a pensarmos o quanto essas estratégias referenciais, exaustivamente estudadas (e, por muito tempo, idealizadas), são naturalmente construídas na interação diária das práticas discursivas humanas e vão se reformulando em novos ambientes de interação, em nosso caso, no aplicativo WhatsAp. Estas estratégias vem sendo bastantes estudadas em relação à linguagem verbal, mas que, de acordo com os resultados mostrados, podem ser aplicadas a outros modos semióticos, também, com as devidas adequações e articulações com as teorias da multimodalidade.

Assim, nossos resultados apontam para uma integração entre os modos semióticos, como o verbal, as imagens e os áudios no intuito de estabelecer a progressão referencial em conversas no aplicativo WhatsApp. Tal integração corrobora não só com a natureza multissemiótica do texto, mas também nos mostra como os processos textuais se articulam para além do verbal, apontando para a potencialidade da integração das demais semioses como um fator importante para a textualidade.

Por fim, entendemos que, dentro dessas condições, o linguístico não está em uma situação hierárquica de superioridade, mas se encontra à disposição das outras semioses e em constante articulação com elas. A linguagem verbal passa a ser vista como mais um dos elementos constitutivos da entidade textual e não como o elemento único e constitutivo da unidade textual. Torna-se, portanto, imprescindível conceber o texto como um elemento multimodal em que as diversas semioses emergem, para uma atuação em conjunto na produção de sentidos, fazendo com que pensemos que a agregação do verbal às demais semioses podem ser um elemento importante para a textualidade.

\section{Referências}

BAUER, M.W; GASKELL, G. Pesquisa qualitativa com texto, imagem e som: um manual prático. Petrópolis, RJ: Editora Vozes, 2002., 520 p.

CAVALCANTE, M. M.; CUSTÓDIO FILHO, V. Revisitando o estatuto do texto. Revista do GELNE, Piauí, v.12, n.2, p. 56-71, 2010.

Cotação. Agrolink. Disponível em: <https://www.agrolink.com.br/cotacoes/frutas/abacate/>. Acesso em: 21 jul. 2018.

DIONÍSIO, A. P. Multimodalidade discursiva na atividade oral e escrita. In: MARCUSCHI, L. A.; DIONÍSIO, A. P. (Orgs.). Fala e escrita. 1. ed., 1. reimp. Belo Horizonte: Autêntica, 2007. p. 177-196.

FERREIRA, N. S.; ARRUDA FILHO, E. J. M. Preferência de uso das redes sociais virtuais para o consumidor tecnológico: uma análise do Facebook versus WhatsApp. In: XVII Seminários em Administração (SEMEAD), XVII edição, 2014, Anais, São Paulo, Universidade de São Paulo, p. 1-16.

FOLHAPE. Governo pressiona PF por prisões para acabar greve. Folha de Pernambuco. Pernambuco, 29 maio 2018.2 Disponível em: $<$ https://www.folhape.com.br/economia/economia/crise-dos-combustiveis /2018/05/29/NWS, 69918,10,1137,ECONOMIA,2373-GOVERNO-PRESSIONA-POR-PRISOES-PARAACABAR-GREVE.aspx>. Acesso em: 29 maio 2018.

HODGE, R.; K, . Social Semiotics. New York: Cornell University Press, 1988, 234 p. 
Volume 14 - Número 2 - ago/dez de 2019

JEWITT, C. The Routledge Handbook of Multimodal Analysis. London: Routledge, 2 ed, 2014, 544 p.

KOCH, I. G. V. Introdução à linguística textual: trajetória e grandes temas. - São Paulo: Martins Fontes, 2004. - (Coleção texto e linguagem). p. 51-79.

KOCH, I. G. V.; ELIAS, V. M. Ler e compreender: os sentidos do texto. - São Paulo: Contexto, 2006, $206 \mathrm{p}$.

MARVERS, D; KRESS, G. Semiótica Social e Textos Multimodais. In: SOMEKH, B; CATHY, C (orgs.). Teoria e Método de Pesquisa Social. Petrópolis, RJ: Editora Vozes, 2015, p. 225-233.

MONDADA, L.; DUBOIS, D. Construção dos objetos de discurso e categorização: Uma abordagem dos processos de referenciação. In: CAVALCANTE, M. M.; RODRIGUES, B. B.; CIULlA, A. (orgs.). Referenciação. - São Paulo: Contexto, 2003. - (Coleção clássicos da linguística). p. 17-52.

MORATO, E. (In)determinação e subjetividade na linguagem de afásicos: a inclinação antireferencialista dos processos enunciativos. Caderno de Estudos Linguísticos. Campinas, v. 41, p. $55-74$, jul/dez. 2001.

RAMOS, P. Estratégias de referenciação em textos multimodais: uma aplicação em tiras cômicas. Linguagem em (Dis)curso, Santa Catarina, v. 12, n. 3, p. 743- 763, set./dez. 2012. 